\title{
An Intra-Household Approach to the Welfare Costs of Inflation ${ }^{\star}$
}

\author{
- Rubens Penha CySNe*
}

\begin{abstract}
RESUMO
A literatura sobre custos de bem estar da inflação assume em geral que famílias compostas por vários membros, com diferentes produtividades na produção do bem de consumo e na função de transação, possam ser modeladas como um único indivíduo representativo. Este trabalho explora as conseqüências de se assumir heterogeneidade entre indivíduos na mesma família. Observam-se impactos sobre a demanda por moeda e, conseqüentemente, sobre os custos de bem-estar da inflação. Mais importante, derivam-se condições de suficiência para que as mensurações de custos de bem-estar que partem do conhecimento da função de demanda por moeda (como em Lucas, 2000)) não sejam afetadas pelo fato de haver heterogeneidade nas famílias (robustez). Por último, demonstra-se que a medida de custo de bem-estar de Bailey (1956) pode ser auferida da medida de equilíbrio geral aqui obtida como uma aproximação de primeira ordem.
\end{abstract}

\section{PALAVRAS-CHAVE}

inflação, bem-estar, moeda, intradomicílio

\begin{abstract}
The literature on the welfare costs of inflation universally assumes that the many-person household can be treated as a single economic agent. This paper explores what the heterogeneity of the agents in a household might imply for such welfare analyses. First, we show that allowing for a one-person or for a many-person transacting technology impacts the money demand function and, therefore, the welfare costs of inflation. Second, more importantly, we derive sufficient conditions under which welfare assessments which depart directly from the knowledge of the money demand function (as in Lucas, 2000) are robust (invariant) under the number of persons considered in the household. Third, we show that Bailey's (1956) partialequilibrium measure of the welfare costs of inflation can be obtained as a first-order approximation of the general-equilibrium welfare measure derived in this paper using a many-person transacting technology.
\end{abstract}

\section{KEY WORDS}

intra-household, inflation, welfare, money

\author{
JEL Classification \\ E40, D60
}

\footnotetext{
+ I am grateful to the participants of workshops at the Getulio Vargas Foundation Graduate School of Economics and at the Department of Economics of the University of Chicago for discussions about this paper.

* Professor at the Graduate School of Economics of the Getulio Vargas Foundation (EPGE/FGV) and Visiting Scholar at the Department of Economics of the University of Chicago. To contact the author: Escola de Pós Graduação em Economia da Fundação Getulio Vargas - Praia de Botafogo 190, $11^{\circ}$ andar - Rio de Janeiro - tel: 21 2559587I. E-mail: rubens@fgv.br.
}

(Recebido em setembro de 2004. Aceito para publicação em novembro de 2005). 


\section{INTRODUCTION}

The literature on the welfare costs of inflation almost universally assumes that the many-person household can be treated as a single economic agent. We shall refer to this treatment as the unitary (U-) model. An example of this approach is given by Lucas (2000). Since households generally consist of several members, one can inquire if taking into consideration this fact would somehow change the conclusions obtained by the use of the U-model.

For instance, in the cash-goods-credit-goods models (e.g., Gillman; 1993; Aiyagari et al., 1998; or English, 1999) one can argue that, due to different opportunity costs of time or to different degrees of access to credit, what is a credit good to one member of the household can be a cash good to another one, and vice versa.

Alternatively, in the shopping-time approach to the welfare costs of inflation (e.g. Lucas, 2000, section 5; Simonsen and Cysne, 2001; or Cysne et al., 2005), on which we shall concentrate here, different members of the household are likely to have different productivities in the production of the consumption good and in transacting. Could it be the case that taking this fact into consideration would change the conclusions obtained by the use of the $\mathrm{U}$ model? This is the point we wish to investigate here.

To foster the intuition about the problem, consider Lucas's shopping-time model (which is a U-model). In such a model, inflation reduces welfare because households end up holding less money and, therefore, have to allocate more of their productive time in transacting. There is an underlying choice of the household regarding how much to hold of real balances and how much time to allocate in transactions. The drop in the production of the consumption good (and in welfare) keeps a one-to-one correspondence (given by the productivity of the agent) with the variation of the household's time allocated in transacting.

Alternatively, consider the same model, but with a many-person optimizing representative household, the members of which share the services of money. Call this the IH (intra-household) model. Here, the decision procedure follows a different pattern, due to the additional degrees of freedom incorporated in the problem. Besides the decision regarding real balances and transacting time, there is also the decision of how to distribute the time of each member of the household between transacting and producing the consumption good.

Given the additional possibilities of the IH- model, one could argue that the welfare costs of inflation determined by the U-model could be upward biased, by not taking 
into consideration that in some families some members with an opportunity cost (measured in terms of the production of the consumption good) close to zero could do all the shopping necessary to make up for the nonsatiation with real balances. If that were true, then there would be no significant drop of production due to the allocation of time into shopping.

In other words, suppose, in a 2-member household, that one of the members has a productivity in the production of the consumption good close to zero, but is very skilled in performing transactions. ${ }^{1}$ Then the welfare might not be as affected by the rise of inflation as one would conclude by using the U-model, because diverting time of this particular member from production to transacting would imply a minor impact on the output of the household, due to her high ratio of productivity in transacting, as compared to productivity in the production of the consumption good.

Investigating if claims like these make sense is one of the purposes of this paper. Actually, one of our important conclusions is that the claim above does not proceed in the usual measurements of the welfare costs of inflation derived under the framework of the U-model. In practical assessments like in Lucas (2000), for instance, the researcher tries to measure the welfare costs of inflation departing from the empirical knowledge of the money demand function. In this case, the same welfare figures emerge, no matter which model (either the U- or the IH- framework) is employed.

A second important conclusion of the work is to show that Bailey's (1956) partialequilibrium measure of the welfare costs of inflation can be obtained as a first-order approximation of our general-equilibrium measure. This result extends previous results obtained by Simonsen and Cysne (2001) and by Cysne (2003) to the framework proposed here.

There is an extensive literature considering the idea of many-person households. Becker (1991) is a recent exposition of Becker's seminal work in this area. Chiaporri (1988) and Browning and Chiaporri (1998) are other references. Our investigation here derives from such ideas. However, our approach differs from the one taken in this literature in two important aspects. First, our analysis is a general-equilibrium and dynamic one, in contrast with the usually partial-equilibrium and static modelling associated with the collective-household literature.

Second, we assume that the different members in a representative multi-person household differ with respect to their relative productivities in producing the consumption good and in transacting, but not with respect to their preferences. The members of

1 The well known "grandma likes going to the bank" claim. 
the representative household are assumed to have the same preferences (or, equivalently, it is assumed that one of the partners can impose her (or his) preferences over the others). This hypothesis allows us to keep the traditional neoclassical approach that assumes the existence of a unique household utility function.

The work proceeds as follows. The $\mathrm{U}$ - and $\mathrm{IH}$ - models are presented in section 1 . Section 2 is dedicated to analyzing the implications, for the derivation of the money demand function and of the welfare costs of inflation, of specifying a single-unit or a multi-unit transacting technology. The analysis is done with and without leisure as an argument of the utility function. Section 3 derives basic conclusions of the analysis. Section 4 compares the IH measure of the welfare costs of inflation with Bailey's (1956) partial-equilibrium measure. Last section offers the final conclusions.

\section{THE MODELS}

\section{The IH-Model}

In this section we depart from the U-model analysis made by Lucas (2000). However, we consider a two-person household, instead of a one-person household, as in the usual U-model case (an extension to an $n$-member household can be done at no cost).

When working with the IH - model, we shall use subindexes 1 and 2 to denote different members of a household. Each member $j$ of the household $(j=1,2)$ has a (fixed) time endowment of one unity. Time is allocated by each member of the household in shopping $\left(s_{i}, 0 \leq s_{i} \leq 1\right)$ and in the production of the consumption good. Member $j$ is assumed to have productivity $a_{j}\left(a_{j} \geq 0, j=1,2\right)$ in the production of the consumption good. $P$ stands for the price of the consumption good.

The total real product $(y=Y / P)$ is given by:

$$
y=a_{1}\left(1-s_{1}\right)+a_{2}\left(1-s_{2}\right)
$$

Households gain utility from the consumption $(c=C / P)$ of a single non-storable consumption good, with preferences determined by:

$$
\int_{0}^{\infty} e^{-g t} U(c) d t
$$


where $U(c)$ is a concave function of the consumption and $g>0$.

Households can accumulate two assets, money $(M)$ and bonds $(B)$, the latter yielding a nominal interest rate equal to $i$. Households face the budget constraint:

$$
\dot{M}+\dot{B}=i B+P\left(a_{1}\left(1-s_{1}\right)+a_{2}\left(1-s_{2}\right)-c\right)+H
$$

$H$ indicates the (exogenous) flow of money transferred by the government and the dot over the variable its time derivative. Making $\pi=\dot{P} / P \quad$ (inflation rate), $m=M / P$, $b=B / P, v=b+m$, and $b=H / P$ the budget constraint in real terms reads:

$$
\dot{v}=a_{1}\left(1-s_{1}\right)+a_{2}\left(1-s_{2}\right)-c+h+(i-\pi) v-i m
$$

The transacting technology is given by:

$$
c=F\left(m, s_{1}, s_{2}\right)=\beta(m) G\left(s_{1}, s_{2}\right)
$$

with $\quad F_{m}=\beta^{\prime}(m) G\left(s_{1}, s_{2}\right)>0, \quad F_{s_{1}}=\beta(m) G_{s_{1}}\left(s_{1}, s_{2}\right)>0, \quad F_{s_{2}}=\beta(m) G_{s_{2}}\left(s_{1}, s_{2}\right)>0$, $F_{m m}=\beta^{\prime \prime}(m) G\left(s_{1}, s_{2}\right)<0, \quad F_{s_{1} s_{1}}=\beta(m) G_{s_{1} s_{1}}\left(s_{1}, s_{2}\right)<0$ and $F_{s_{2} s_{2}}=\beta(m) G_{s_{2} s_{2}}\left(s_{1}, s_{2}\right)<0 . G$ is concave and first-degree homogenous.

The transacting technology shows how each one of the inputs, shopping time of member one, shopping time of member two, and money, can be used by the household in the acquisition of the consumption good. We assume that the members of the household pool their transaction balances.

This transacting technology can be justified in the same way as the one in Cysne (2003). Here, though, instead of pooling different currencies, the household is assumed to pool the times of its members. This is formally done through the use of the aggregating function $G\left(s_{1}, s_{2}\right)$ used in (4).

The microfoundations for a transacting technology of the type $c=F(m, s)$ are based on the inventory-technology found in the works of Baumol (1952), Tobin (1956) and Miller and Orr (1966). Lucas (1993, p. 13 and 14) and Lucas (2000, p. 265 - see, in particular, footnote 13) discuss how this transacting technology can be obtained from the work of the authors cited above and mention how it features in some monetary models in the literature. Equation (4) extends the transacting technology $c=F(m, s)$ used in Lucas (2000) to the case $c=F(m, G)$, where $G$ is an aggregator function which aggregates the shopping time of the members of the household. The same type 
of aggregator function has been used by Simonsen and Cysne (2001), Cysne (2003) and Cysne et al. $(2004,2005)$ regarding the aggregation of monetary assets, rather than of shopping times.

Households maximizes (2) subject to the budget constraint (3) and to the timetransacting technology (4). As in Lucas (2000) and Cysne (2003) and Cysne et al. (2005), the Hamiltonian in this case is not concave, which means that the usual Mangasarian's sufficient conditions cannot be used. As in these three papers cited, this implies that the characterization of optimality here is only provided in terms of necessity, rather than of sufficiency. ${ }^{2}$

In the steady state, assuming interior solutions, Euler equations lead to the necessary conditions (5), (6) and (7) below:

$$
\begin{gathered}
i=\pi+g \\
a_{1} F_{m}=i F_{s_{1}} \\
a_{2} F_{m}=i F_{s_{2}}
\end{gathered}
$$

The equilibrium equation:

$$
a_{1}\left(1-s_{1}\right)+a_{2}\left(1-s_{2}\right)=F\left(m, s_{1}, s_{2}\right)
$$

completes the model.

Given the interest rate $i$, the variables $m, s_{1}$ and $s_{2}$ are determined by equations (6), (7) and (8).

In this shopping-time framework, as in Lucas (2000), the welfare costs of inflation are defined as the output loss due to the allocation of time in transacting. The reason for doing so is that in this economy all monetary services could be provided, if there were no costs of holding money, by having households make $m \rightarrow \infty$ (total satiation of real balances). In the present model the output loss due to having both $s_{1} \neq 0$ and $s_{2} \neq 0$ is equal to $a_{1} s_{1}+a_{2} s_{2}$, the time spent on transaction weighed by the respective

2 For a treatment of the problem of nonconvexity concerning some papers in the shopping-time and in the human-capital literature using Arrow's sufficiency theorem see Cysne $(2004,2006)$. 
productivity of each member of the household. This is, therefore, the expression for the welfare costs of inflation.

\section{The U-Model}

The U-model versions of equations (1), (3) and (4) are given by, respectively:

$$
\begin{aligned}
& y=1-s \\
& \dot{v}=1-s-c+h+(i-\pi) v-i m
\end{aligned}
$$

and

$$
c=F^{U}(m, s)
$$

where the superscript $U$ in $F$ stands for the U-model.

The U-model here is the same as the one in Lucas (2000, Section 5).

The equilibrium equations describing the U-model (to be compared, respectively, with (6), (7) and (8) are:

$$
\begin{aligned}
& F_{m}^{U}=i F_{s}^{U} \\
& 1-s=F^{U}(m, s) .
\end{aligned}
$$

\section{Government}

In both models, the economy is endowed with lump sum taxation, where the government can implement any given interest rate. In equilibrium, the rate of money expansion and inflation is determined so that the seigniorage matches the transfers (b) plus net real interest payments made by the government:

$$
h=\pi m-(i-\pi) b
$$

The relation between the rate of inflation and the rate of interest is given by (5). Inflation is equal to the rate of monetary expansion, the exogenous variable of the model. 


\section{SINGLE-UNIT VERSUS MULTI-UNIT TRANSACTING TECHNOLOGIES}

In this section we investigate the effects, on the money demand and on the welfare costs of inflation, of using a multi-unit transacting technology, vis-à-vis the usual approach of adopting a single-unit technology. This will enable us to understand, for instance, how biased can be a theoretical analysis based on a single-unit household, when the household is actually comprised of many different members. We shall see that the discrepancies among the relative productivities of the members of the household in the production of the consumption good and in transacting play an important role.

We interpret the U-model as a restricted version of the IH-model by making

$$
\begin{aligned}
& a_{1}+a_{2}=1 \\
& \left.F^{U}(m, s) \equiv F\left(m, s_{1}, s_{2}\right)\right|_{s_{1}=s_{2}=s}
\end{aligned}
$$

Equation (14) implies that in both models output is normalized to one when the representative household allocates the totality of its time endowments in the production of the consumption good. Equation (15) defines the transacting technology in the $\mathrm{U}$-model as a restricted version of the transacting technology in the IH-model.

To start with, note that the restriction of $F$ to $s_{1}=s_{2}$ in (15) will be binding when different members of a household have different relative productivities in transacting and in producing the consumption good. Example 1 below clarifies this point. In Example 1 members one and two, of a given household, are treated symmetrically with respect to the transacting technology, but are allowed to have different productivities in the production of the consumption good.

It is not our purpose here to provide a calibration of the model. The simulations presented in the example below, as well as in example 2, to follow, aim solely at providing comparisons between the welfare figures that emerge in each one of the two cases (the U-model versus the IH-model).

Example 1- Consider the transacting technology $F\left(m, s_{1}, s_{2}\right)=m s_{1}^{0.5} s_{2}^{0.5}$. After using equations (6), (7) and (8), the solution for the IH- model is given by:

$$
\begin{aligned}
& s_{1}=0.5 \mathrm{im} / a_{1} \\
& s_{2}=0.5 \mathrm{im} / a_{2}
\end{aligned}
$$


where $m$ is determined as the positive root of

$$
g_{1}(m)=m^{2}+\frac{1}{\alpha} m-\frac{1}{i \alpha}
$$

and $\alpha=0.5 / \sqrt{a_{1} a_{2}} \geq 1$ (remember (14)). As explained before, the total welfare cost of inflation in this case is given by $a_{1} s_{1}+a_{2} s_{2}$. In the present model, this is also equal to im, the inflation tax. ${ }^{3}$ After using equations (12) and (13), the expression for the welfare cost of inflation in the U-model is given by $s=i m$, where $m$ now is determined as the positive root of:

$$
g_{2}(m)=m^{2}+m-\frac{1}{i}
$$

We show in the appendix that the positive root of $g_{2}(m)$ is always greater or equal than the positive root of $g_{1}(m)$ and that both roots are less than $1 / i$ (this last remark ensuring that $a_{1} s_{1}+a_{2} s_{2}<1$ and $s<1$, as required by the model). The equality, between the two models, of the equilibrium demand for money and of the implied welfare costs of inflation happens iff $a_{1}=a_{2}=0.5$ (what makes $\alpha=1$ ). As one would expect, this is the case in which the restriction $s_{1}=s_{2}=s$ is not binding. Both members of the household are treated symmetrically with respect to the transacting technology and have the same productivity in the production of the consumption good. Table 1 shows how the welfare costs of inflation vary when one allows for different productivity ratios of the two members of the household.

TABLE 1 - WELFARE COSTS OF INFLATION (\%GDP) IN THE STANDARD (U-) MODEL AND IN THE IH- MODEL

\begin{tabular}{cccc}
\hline $\begin{array}{c}\text { Yearly Interest } \\
\text { Rate }\end{array}$ & $\begin{array}{c}\text { Standard (U-) Model } \\
\left(a_{1} / a_{2}=1\right)\end{array}$ & $\begin{array}{c}\text { IH-Model } \\
a_{1} / a_{2}=20\end{array}$ & $\begin{array}{c}\text { IH-Model } \\
a_{1} / a_{2}=100\end{array}$ \\
\hline 0.03 & 0.96 & 0.64 & 0.45 \\
0.14 & 1.88 & 1.31 & 0.93 \\
0.50 & 3.02 & 2.22 & 1.62 \\
1.0 & 3.73 & 2.86 & 2.15 \\
\hline
\end{tabular}

3 The result obtained in this example, by which the welfare costs of inflation $\left(a_{1} s_{1}+a_{2} s_{2}\right)$ reads as a mirror image of the inflation tax $(\mathrm{im})$ is not new in the literature. It has been obtained before by Lucas (1993, p. 14, eq. 4.14), by Lucas (2000, p. 266) and generalized by Simonsen and Cysne (2001, eq. 33, p. 98), for the case in which there is a second monetary asset in the economy. 
One concludes from the observation of lines one and two of the table, for instance, that a gain around $0.9 \%$ of GDP, when yearly interest rates drop from $14 \%$ to $3 \%$ can actually be no greater than $0.48 \%(0.93 \%-0.45 \%)$ (last column of the Table) of GDP, if one allows for different productivities across the members of a household. The bigger the difference in productivities (moving from left to right along any line), the smaller the welfare figures. The table also suggests that the higher the interest rates, the higher the discrepancies (as a percentage of GDP), between the estimates of the U-model and those of the IH model.

\subsection{Leisure}

So far we have assumed that the members of a household did not value leisure. This subsection aims at investigating how the previous results might be affected when leisure is included as one of the arguments of the utility function.

For simplicity, the calculations below are restricted to having $l_{1}=l_{2}=l$, where $l$ stands for leisure and the subindices 1 and 2 have the same meaning as before.

We shall conclude, as above, that the welfare figures that emerge from the IH-model are lower than the ones associated with the U-model. Moreover, the relative discrepancies between the IH-model and the U- model are lower when one considers that households derive utility from leisure.

Household members are now assumed to maximize:

$$
\int_{0}^{\infty} e^{-g t} U(c, l) d t
$$

\section{The IH-Model With Leisure}

Constraint (14) remains the same. However, constraint (3) is altered by the inclusion of the time dedicated to leisure:

$$
\dot{v}=a_{1}\left(1-s_{1}\right)+a_{2}\left(1-s_{2}\right)-c-l+h+(i-\pi) v-i m
$$

Besides the usual first order conditions (6) and (7), one has:

$$
U_{l}=\frac{U_{c} F_{s_{1}}}{a_{1}+F_{s_{1}}}=\frac{U_{c} F_{s_{2}}}{a_{2}+F_{s_{2}}}
$$


The new equilibrium equation:

$$
1-a_{1} s_{1}-a_{2} s_{2}-l=F\left(m, s_{1}, s_{2}\right)
$$

completes the IH-model. Equations (6), (7), (18) and (19) determine $s_{1}, s_{2}, l$ and $m$ as a function of the interest rate $i$.

\section{The U-Model With Leisure}

Proceeding like in section 1 , the first-order and equilibrium conditions of the usual single-member-household are now given by (12), and by:

$$
\begin{aligned}
& U_{l}=\frac{U_{c} F_{s}^{U}}{1+F_{s}^{u}} . \\
& 1-s-l=F^{U}(m, s) .
\end{aligned}
$$

Equations (12), (20) and (21) determine $s, m$ and $l$ as a function of the nominal interest rate in the U-model. Example 2 illustrates the quantitative aspects of this case.

Example 2 - The estimates of this example are based on the same transacting technology of Example 1, and on an utility function $u(c, l)=l^{1-\beta} c^{\beta}$. Using the first-order conditions and the equilibrium equation of the IH- model:

$$
\begin{aligned}
s_{1} & =0.5 i m / a_{1} \\
s_{2} & =0.5 i m / a_{2} \\
l & =\frac{i m(1-\beta)}{\beta}(1+\alpha m)
\end{aligned}
$$

where $\alpha$ has the same definition as in Example 1 and now $m$ is determined as the root of the following equation:

$$
g_{1 l}(m)=m^{2}+\frac{m}{\alpha}-\frac{\beta}{\alpha i}=0
$$

Alternatively, the first order and equilibrium equations (12), (20) and (21) lead to $s=i m, m$ being determined as the positive root of:

$$
g_{2 l}(m)=m^{2}+m-\frac{\beta}{i}
$$


As in the previous example, the positive root of $g_{2 l}(m)$ is greater than the positive root of $g_{1 l}(m)$. Also, both roots are less than $\frac{\beta}{i}$, ensuring $a_{1} s_{1}+a_{2} s_{2}<1$ and $s<1$ (see appendix). The equality of the welfare costs happens iff $a_{1}=a_{2}=0.5$ (what makes $\alpha=1$ ), Table 2 presents some welfare figures under different productivity ratios when $\beta=0.5$.

\section{TABLE 2 - WELFARE COSTS (\%GDP) WITH DIFFERENT IH- PRODUC- TIVITIES}

\begin{tabular}{cccc}
\hline $\begin{array}{c}\text { Yearly Interest } \\
\text { Rate }\end{array}$ & $\begin{array}{c}\text { Standard Model } \\
a_{1} / a_{2}=1\end{array}$ & $\begin{array}{c}\text { Two-Members Model } \\
a_{1} / a_{2}=20\end{array}$ & $\begin{array}{c}\text { Two-Members Model } \\
a_{1} / a_{2}=100\end{array}$ \\
\hline 0.03 & 0.65 & 0.45 & 0.31 \\
0.14 & 1.23 & 0.88 & 0.63 \\
0.50 & 1.87 & 1.43 & 1.08 \\
1.0 & 2.21 & 1.78 & 1.39 \\
\hline
\end{tabular}

The conclusions are basically the same as those obtained from Table 1, except for the fact that the relative discrepancies among the welfare figures, either along each line or each column, are usually lower than before.

\section{EQUIVALENCE IN EMPIRICAL ASSESSMENTS}

In empirical studies, what is usually known by the researcher is the money demand, not the transacting technology. Therefore, usual estimates of the welfare costs of inflation have to deal with the problem of recovering the welfare figures from the knowledge only of the money demand. Such a procedure has been used by Lucas (2000), Simonsen and Cysne (2001), and generalized by Cysne (2003). This section uses basically the same approach of these authors to generalize the procedure in the case of the particular multi-member transacting technology we are using.

The main result is that such welfare measurements (which, as in Lucas (2000), depart from the empirical knowledge of the money demand), are invariant (robust) under the number of members considered in the representative household. The result uses the fact that the transacting technology aggregates the shopping times of different members of the household with a first-degree homogenous function $G$, as it has been assumed in (4). 
Proposition 1 - Suppose that the transacting technology is given by (4). Then, welfare measurements which abstract directly from the knowledge of the money demand lead to the same results, either under the U- model or under the IH-model.

Proof: From (6), (7) and (8), the first order and equilibrium equations for the problem, in this case, are:

$$
\begin{aligned}
& a_{1} \beta^{\prime} G=i G_{s_{1}} \beta . \\
& a_{2} \beta^{\prime} G=i G_{s_{2}} \beta . \\
& 1-a_{1} s_{1}-a_{2} s_{2}=G \beta .
\end{aligned}
$$

The homogeneity of $G$ implies:

$$
\left(a_{1} s_{1}+a_{2} s_{2}\right) \beta^{\prime}=\beta i
$$

Differentiating (24) with respect to $i$, and using (22) and (23):

$$
-a_{1} s_{1}^{\prime}-a_{2} s_{2}^{\prime}=\left(\frac{a_{1} s_{1}^{\prime}+a_{2} s_{2}^{\prime}}{i}+m^{\prime}\right) G \beta^{\prime}
$$

Given (24) and (25):

$$
-a_{1} s_{1}^{\prime}-a_{2} s_{2}^{\prime}=i m^{\prime}(i)\left(1-a_{1} s_{1}-a_{2} s_{2}\right)
$$

Denoting the welfare costs of inflation $a_{1} s_{1}+a_{2} s_{2}$ by $z$,

$$
z^{\prime}(i)=-i m^{\prime}(i)(1-z(i)), z(0)=0
$$

Assuming that the money demand function has been previously estimated, (26) allows for the measurement of the welfare costs of inflation $z$. The proof is complete by noticing that the counterpart of equation (4), in the case of the U-model, is given, consistently with the first degree homogeneity of $G$, by $F^{U}(s, m)=s \beta(m)$. Proceeding from this equation and using (12) and (13) leads to (26), with $s$ replacing $z$.

Despite the result established by Proposition 1, there is a subtle difference between the two analyses. In the usual U-model, the transacting technology can be recovered from equation $1-s=s \beta(m)$, once $s$ has been calculated. However, such a procedure 
is not possible in the IH-model, unless additional information is available (for instance, the time allocated by each member of the household in transacting and in production).

\section{A COMPARISON WITH BAILEY'S FORMULA}

Here we compare the welfare expression that emerges from our model with Bailey's (1956) partial-equilibrium one. As it is well known, Bailey's formula for the welfare costs of inflation $(B)$ is given by:

$$
B^{\prime}(i)=-i m^{\prime}(i), B(0)=0
$$

Proposition 2 - Bailey's welfare formula is an upper bound to the IH-measure of welfare costs of inflation $z(i)$ given by (26).

Proof: Suffices noticing in (26) and (27) that $0<1-z<1.4$

The comparison between $B$ and $z$ can be further improved by the Proposition below:

Proposition 3 - The general-equilibrium expression for the welfare costs of inflation $z$ relates to Bailey's formula $B$ accordingly to:

$$
z(i)=1-\exp (-B)
$$

Proof: From (26):

$$
\int_{0}^{z} \frac{z^{\prime}(x)}{1-z(x)} d x=\int_{0}^{i}-i m^{\prime}(i) d i
$$

Integrating both sides and using the initial-value conditions $z(0)=B(0)=0$ leads to (28).

Proposition 4 - Bailey's partial-equilibrium formula is a first-degree approximation to the general-equilibrium welfare measure $z$.

4 Simonsen and Cysne (2001) present a similar conclusion using another transacting technology that leads to a non-separable version of (26). 
Proof: The difference $B-z$ is given by the series $\sum_{k=2}^{\infty} B^{k} / k !$. Since $0<B<1$, this series is convergent.

Note that the series $\sum_{k=2}^{\infty} B^{k} / k$ ! converges to a positive number, consistently with Proposition 2.

\section{CONCLUSIONS}

We have presented an analysis of the welfare costs of inflation that, in contrast with the usual literature, takes into consideration the fact that households are generally comprised of more than one single member.

By allowing different members in a household to have different relative productivities in the production of the consumption good and in transacting, we have seen that the usual unitary (U-) model and the intra-household ( $\mathrm{IH}-$ ) model can lead to different money demands and, therefore, to different figures concerning the welfare costs of inflation. Welfare costs are usually larger in the U-model, as compared to the IHmodel, with the relative discrepancy between the models decreasing when the utility derived from leisure is taken into consideration.

We have also concluded that under blockwise weakly separability and first-degree homogeneity of the transacting technology with respect to the shopping time of each member of the household, empirical assessments of the welfare costs of inflation which depart directly from the knowledge of the money demand lead to the same result, either considering a single unit or a multi-unit household. This point is important because it shows that welfare calculations such as those performed by Lucas (2000) are invariant (or robust) with respect to the modelling alternatives considered here.

Finally, we have derived a closed-form expression for the difference between Bailey's (1956) partial-equilibrium and the general-equilibrium expression of the welfare costs of inflation (valid for any money demand function) and concluded that Bailey's measure, besides being an upper bound to the IH-measure, can be interpreted as a firstorder approximation to the general-equilibrium one. 


\section{APPENDIX}

Here we show, as required in the examples 1 and 2, that the positive root of $g_{2 l}(\mathrm{~m})$ of example 2 ( or $g_{2}(m)$ in example 1 ) is always greater or equal than the positive root of $g_{1 /}(m) \quad\left(g_{1}(m)\right.$ in example 1$)$. We provide two alternative proofs:

Proof 1 - Starting with the second example, it suffices noticing that, if $m_{1 /}$ and $m_{2 /}$ stand, respectively, for the positive roots of $g_{1 /}(m)$ and $g_{2 /}(m)$, then $g_{1 l}\left(m_{2 l}\right) \geq 0$. Proceeding with the calculations:

$$
g_{1 l}\left(m_{2 l}\right)=A(\alpha-1)(1+2 \beta / i-\sqrt{1+4 \beta / i})
$$

where $A>0$. Since $\alpha \geq 1$ and $1+2 \beta / i-\sqrt{1+4 \beta / i}>0$ when $\beta / i>0, \quad g_{1 l}\left(m_{2 l}\right) \geq 0$. Also, observe that the equality occurs iff the productivities of both agents in the production of the consumption good is the same $(\alpha=1)$. The same conclusions apply to Example 1 by making $\beta=1$ above.

Proof 2 - ain, we start with the second example. Observe that (for $k=1 / \alpha$ ) the positive root of the family of quadratic equations $f(x)=x^{2}+k x-k \beta / i, k>0$ is always less than $b / i$. Since this root $\left(x^{*}\right)$ satisfies $x^{* 2}+k x^{*}-k \beta / i=0$, the application of the implicit function theorem leads to $d x^{*} / d k=-\left(x^{*}-\beta / i\right) / \sqrt{k^{2}+4 k \beta / i}>0$. The result follows by noticing that, since $\alpha \geq 1$, the value of $k$ in $g_{1 /}(m)$, equal to $1 / \alpha$, is lower than in $g_{2 /}(m)$ (equal to one). The proof for the first example follows the same steps, by taking $\beta=1$.

\section{REFERENCES}

Aiyagari, S.; Rao, R.; Braun, Anton; Eckstein, Zvi. Transaction services, inflation, and welfare. Journal of Political Economy, 106, p. 1274-1301, 1998.

Bailey, Martin J. Welfare cost of inflationary finance. Journal of Political Economy 64, p. 93-110, 1956.

Baumol, William J. The transactions demand for cash: an inventory-theoretic approach. Quarterly Journal of Economics 66, p. 545-556, 1952.

Becker, G. S. A treatise on the family. Cambridge and London: Harvard University Press, 1991.

Browning, M.; Chiaporri, P. A. Efficient intra-household allocations: a general characterization and empirical tests. Econometrica, v. 66, n. 6, November 1998. 
Chiaporri, P. A. Rational household labor supply. Econometrica, v. 56, issue 1, p. 63-90, 1988.

Cysne, Rubens P. Divisia index, inflation and welfare. Journal of Money, Credit and Banking, v. 35, n. 2, p. 221-239, 2003.

. Solving the non-convexity problem in some shopping-time and humancapital models. Ensaio Econômico da EPGE n. 567, 2004; Forthcoming, Journal of Banking and Finance, 2006.

Cysne, Rubnes Penha; Maldonado, Wilfredo; Monteiro, Paulo Klinger. K. Inflation and income inequality: a shopping-time approach. Journal of Development Economics, United States, v. 78, p. 516-528, 2005.

English, William B. Inflation and financial sector size. Journal of Monetary Economics 44 , p. 379-400, 1999

Gillman, Max. The welfare cost of inflation in a cash-in-advance economy with costly credit. Journal of Monetary Economics, 31, p. 97-115, 1993.

Lucas Jr., R. E. Inflation and welfare. The University of Chicago, 1993. Mimeo. 2000 . Inflation and welfare. Econometrica, v. 68, n. 62, p. 247-274, March

Miller, Merton H.; Orr, Daniel. A model of the demand for money by firms. Quarterly Journal of Economics 77, p. 405-422, 1966.

Simonsen, Mario H.; Cysne, Rubens P. Welfare costs of inflation and interest-bearing deposits. Journal of Money Credit and Banking, v. 33, n. 1, p. 90-101, February 2001.

Tobin, James. The interest elasticity of the transactions demand for cash. Review of Economics and Statistics 38, p. 241-247, 1956. 